\title{
Contact With Nature as a Mental Health Buffer for Lower Income Communities During the COVID-19 Pandemic
}

\author{
Amber L. Pearson ${ }^{1 *}$, Teresa Horton ${ }^{2}$, Karin A. Pfeiffer ${ }^{3}$, Rachel Buxton ${ }^{4}$, \\ Joseph Gardiner ${ }^{5}$, Wei Liu ${ }^{1}$, Ruth F. Hunter ${ }^{6}$ and Mathew P. White ${ }^{7}$ \\ ${ }^{1}$ Department of Geography, Environment and Spatial Sciences, Michigan State University, East Lansing, MI, United States, \\ ${ }^{2}$ Department of Anthropology, Northwestern University, Evanston, IL. United States, ${ }^{3}$ Department of Kinesiology, Michigan \\ State University, East Lansing, MI, United States, ${ }^{4}$ Department of Biology, Carleton University, Ottawa, ON, Canada, \\ ${ }^{5}$ Department of Epidemiology and Biostatistics, Michigan State University, East Lansing, MI, United States, ${ }^{6}$ Centre for \\ Public Health, Queen's University Belfast, Belfast, Ireland, ${ }^{7}$ Cognitive Science HUB, University of Vienna, Vienna, Austria
}

\section{OPEN ACCESS}

Edited by:

Michelle Leigh Johnson, United States Forest Service (USDA),

United States

Reviewed by:

Paunita Iuliana Boanca, University of Agricultural Sciences and Veterinary Medicine of

Cluj-Napoca, Romania Christoph Randler, University of Tübingen, Germany

*Correspondence: Amber L. Pearson apearson@msu.edu

Specialty section: This article was submitted to Urban Resource Management, a section of the journal

Frontiers in Sustainable Cities

Received: 30 March 2021

Accepted: 26 July 2021

Published: 19 August 2021

Citation:

Pearson AL, Horton T, Pfeiffer KA,

Buxton R, Gardiner J, Liu W, Hunter RF and White MP (2021) Contact With Nature as a Mental

Health Buffer for Lower Income Communities During the COVID-19

Pandemic.

Front. Sustain. Cities 3:688473. doi: 10.3389/frsc.2021.688473
Despite a growing number of research outputs on the importance of nature contact during the COVID-19 pandemic, we know of no longitudinal research conducted prior to and during the pandemic among low-income and minority ethnicity populations, i.e., those that might be most affected. Furthermore, we have scant information about how and to what degree contact with nature might protect mental health or mitigate worsening of mental health during the pandemic. We filled these gaps using a subset of a longitudinal study of $n=86$ individuals in low-income, predominantly African American, neighborhoods in Detroit, MI, USA. The study addressed the following research questions: (1) did self-reported use and perceived value of nature change during, vs. prior to, the pandemic; (2) did perceived access to outdoor spaces buffer people against mental health issues such as stress, anxiety and depression symptoms; or (3) did objectively measured quality of nature views from home buffer people against mental health issues, taking into account relevant covariates and pandemic experiences (e.g., loss of employment, death of a friend/relative)? While attitudes to nature improved slightly from pre- to during the pandemic, we also observed significant decreases in most types of outdoor physical activity and passive enjoyment of nature (e.g., smelling plants/rain). We found a positive association between visibility of greenspace and perceived stress and anxiety, which not only contradicts previous research findings, but was especially surprising given that overall there was a decrease in perceived stress from 2019-2020. We did not detect associations between perceived access/use of nature and mental health. However, higher depressive symptoms were associated with exposure to more COVID-19-related stressors (lost employment, death of friends from COVID-19, etc.). Taken together, our results indicate that COVID-19 may serve to prolong or exacerbate mental health issues, rather than create them, in this population and that low quality greenspace may perhaps limit the ability for nature view to buffer mental health during the pandemic.

Keywords: green space, viewshed, equity, African American, stress, parks, anxiety 


\section{INTRODUCTION}

During the early months of the pandemic, stories about increased wildlife in urban spaces, usage of parks in record numbers, and even conflict related to accessing public open spaces abounded in the popular media. For example, beaches and national parks have been sites of contestation related to accessibility of sites, crowded conditions, and deterioration of natural spaces due to over-use. Such record accounts of usage of natural spaces implies these areas may be important to the public during times of crises like a pandemic (Volenec et al., 2021). Indeed, at a time when being indoors with others is not recommended to limit the spread and potential exposure to COVID-19, many people have sought refuge in public, outdoor spaces. However, many national parks and large natural areas are not easily accessible to urban residents, particularly communities of color (Xiao et al., 2017).

Also during the pandemic, many people report higher stress and anxiety related to COVID-19 infection risk and the cascading effects of the pandemic on economic and social conditions (Ettman et al., 2020). What is less understood is how and to what degree contact with nature might protect mental health during the pandemic. Understanding whether mental health outcomes appear to be better for those who are able to engage in outdoor activities or have better views of nature from home may provide insights into strategies to improve mental health during crises, such as the COVID-19 pandemic.

Building on several decades of research on the physical and mental health benefits (e.g., cognition, blood pressure, stress, sleep) of contact with nature (Berman et al., 2008; Kuo, 2015; Shanahan et al., 2016; Cox et al., 2017; Frumkin et al., 2017; Taylor et al., 2017), emerging COVID-19 research indicates that contact with nature may also buffer against the stress associated with pandemic conditions, including lockdown (Pouso et al., 2020). Investigators showed that, in Europe, those with a selfreported view of nature from home (green and/or blue space) had lower anxiety and depression, compared to those with selfreported views of built-up areas. Moreover, those who reported lost employment and had lower access to shared outdoor spaces had higher anxiety and depression than other groups. In contrast, evidence from Scotland did not detect associations between spending time in nature and changes in health from prelockdown levels (Corley et al., 2021). Likewise, the number of nature interactions was also not associated with loneliness, while living far from nature was in the Netherlands (van HouwelingenSnippe et al., 2020), suggesting that passive exposure to nature may be important.

Other research has shown increased nature-related activities in and value of nature in the US (Morse et al., 2020) and significant changes in patterns of visiting nature as a result of the COVID-19 pandemic in the UK (Robinson et al., 2021). Not only did frequency of nature-related activities change, but so did the locations, with some research reporting increased usage of nearby or neighborhood natural areas (Randler et al., 2020; Portegijs et al., 2021). Poor quality neighborhood conditions, thus, appear to be important factors in exacerbating mental health disparities during the pandemic (Yang and Xiang, 2021).
Taken together, the emerging research touches upon two primary pathways through which contact with nature is believed to influence health: (1) passive exposure (e.g., visual, auditory) and (2) active exposure (e.g., ability to use the space). Although this emerging research is compelling and involves a large sample size and wide swathe of countries, there are several missing components that would advance our understanding of the role of nature in decreasing the adverse impacts of stress. Research is needed, namely, on the importance of nature contact among low-income populations and communities of color, given the disproportionate impact of COVID-19 on these communities (Abedi et al., 2020; Mackey et al., 2020; Tirupathi et al., 2020), inclusion of data from before and during the pandemic about usage behaviors, and objective quantification of visual contact with nature.

Given this background, this paper addressed the following research questions: (1) did self-reported use and perceived value of nature change during, vs. prior to, the pandemic; (2) did perceived access to outdoor spaces buffer people against mental health issues such as stress, anxiety and depression symptoms; or (3) did objectively measured quality of nature views from home buffer people against mental health issues, taking into account relevant covariates and pandemic experiences (e.g., loss of employment, death of a friend/relative)?

\section{MATERIALS AND METHODS Ethical Approval}

The study was approved by the Michigan State University's Institutional Review Board (IRB Approval \#STUDY00000587; date 03/21/2019 and modified for COVID conditions $05 / 26 / 2020$ ). Informed consent was obtained in writing from all participants.

\section{Sample, Recruitment, and Retention}

This study involves a subset of participants in a larger, longitudinal study of the benefits of park restoration on health (see Pearson et al., 2020 for more details). Sampling for the parent study was conducted in two stages. First, neighborhoods $(n=$ 9) were selected that contain a park not currently maintained by the Detroit Parks and Recreation Department as a conventional park. Second, to recruit participants, we mailed postcards and conducted recruitment activities (e.g., information booths) in each selected neighborhood (defined as $500 \mathrm{~m}^{2}$ with a park as the center). Participants were recruited from within a 16-cell grid $\left(120 \mathrm{~m}^{2} /\right.$ cell $)$ around each park. Longitudinal data collection for the parent study is scheduled to occur every May-October until 2023.

In August-October 2019 (late funding led to a truncated field season), field staff visited homes in each study neighborhood to brief potential participants on the study, request participation, and screen for inclusion. We recruited only one English-speaking male or female ( $\geq 18 \mathrm{y}$ ) without mobility issues per household, which was at the household's discretion ( $n=145$ participants). In 2020, however, due to IRB restrictions during the COVID-19 pandemic, no new recruitment took place. Instead, we modified our protocol to collect contactless data. In 2020, we contacted and 
obtained data for a subset of 86 of the participants from the 2019 wave $(52 \%)$ from June 15 th to July 29 th. To retain participants between 2019 and 2020, we employed a set of strategies including: (1) sending holiday cards with neighborhood-level study results; (2) sending birthday cards; and (3) adding news items and updates through the study website (www.stand-detroit.org).

\section{Survey and Anthropometrics}

In 2019, a paper survey was given to participants at enrollment, and anthropometrics were taken at a scheduled office health appointment. At the appointment, height was measured twice using a stadiometer (SECA Corp), and weight was measured twice using a scale with bioelectric impedance capability (Tanita TBF-300). Measures were then averaged, and BMI was calculated as a ratio of weight and height $\left(\mathrm{kg} / \mathrm{m}^{2}\right)$. The paper survey was returned during the health appointment.

In 2020, a paper survey was provided in a packet along with a sanitized scale, both placed on a participant's front porch/apartment entry door, while a field staff member waited in a car nearby and watched as the participant retrieved the packet and took their weight on the scale. The participant then phoned or texted their weight and went indoors while the field staff member retrieved and sanitized the scale. Staff returned 3-5 days later to retrieve the paper survey.

Throughout this study, the paper survey was self-administered and completed in the privacy of participants' own homes. The survey included basic demographic data information (age, sex, ethnicity, employment, household composition, length of residence), income, perceptions of the neighborhood (Saelens et al., 2003; Forsyth et al., 2009; Schroeder and Wilbur, 2013; Prouse et al., 2015; Ramos et al., 2016), disease and prescription medication history [National Eye Institute, 2000; Cantor et al., 2009; Audiometry Questionnaire (AUQ), 2018; NHANES, 2018], diet (NHANES, 2010; Nebeling et al., 2017), perceived stress or PSS (Cohen et al., 1983), anxiety and depressive symptoms (Cella et al., 2007; Hays et al., 2009), and attitude toward nature (Nature-relatedness 6, NR-6) (Nisbet and Zelenski, 2013).

In 2020, we also included pandemic-related questions including before and during COVID-19 outdoor physical activities, value of nature, perceived access to nature, and social and economic effects of COVID-19. These questions were registered in the COVID-19 PhenX Toolkit (Community Access module at https://www.phenxtoolkit.org/toolkit_content/ PDF/MSU_CWC_Community.pdf). Using a similar approach to Ettman et al. (2020), we generated a "stressor score" which summed all positive agreement for the effects of COVID-19 on life conditions into one value (variables included in Table 1), which ranged from low stressors (0) to high stressors (Ettman et al., 2020) (mean $=1.4, s d=1.5)$.

\section{Viewshed Analyses}

The viewshed, or area visible from participants' homes, was assessed objectively using previously described methods (Nutsford et al., 2015). In brief, we first defined the visibility analysis study area (VASS) as the city boundary of the city of Detroit plus a $12 \mathrm{~km}$ buffer. We clipped the VASS using the US/Canada border so that only the area within the US
TABLE 1 | Sample demographics and health status in 2019 and 2020

\begin{tabular}{|c|c|c|c|}
\hline Characteristic & 2019 & 2020 & $p$-value ${ }^{\ddagger}$ \\
\hline Income, $\%<\$ 10,000$ & 32.1 & 40.5 & 0.375 \\
\hline Employed, \% & 17.9 & 23.8 & 0.424 \\
\hline Married/partnered, \% & 15.5 & 33.3 & $<0.001$ \\
\hline Own home, \% & 27.4 & 35.7 & 0.375 \\
\hline Sick in past two weeks, \% & 17.9 & 9.5 & 0.302 \\
\hline Age (in years), mean (sd) & $56.0(14.3)$ & $56.8(14.6)$ & - \\
\hline Number of children living at home, mean (sd) & $0.4(1.1)$ & $0.3(1.0)$ & 0.159 \\
\hline Attitude toward nature, mean (sd) & $3.0(0.8)$ & $3.3(1.1)$ & 0.010 \\
\hline Current smokers, \% & 51.2 & 38.1 & 0.250 \\
\hline Overweight or obese, \% & 73.8 & 67.9 & $>0.999$ \\
\hline BMl, mean (sd) & $31.2(8.2)$ & $31.5(8.9)$ & 0.170 \\
\hline PSS score, mean (sd) & $19.8(5.1)$ & $15.8(5.4)$ & 0.001 \\
\hline Anxiety t-score, mean (sd) & $55.5(9.7)$ & $53.9(10.1)$ & 0.266 \\
\hline Depression t-score, mean (sd) & $52.7(10.0)$ & $51.8(10.2)$ & 0.418 \\
\hline My employment has stopped. ${ }^{\S}$ & & $2.7(1.3)$ & \\
\hline My income has stopped..$^{\S}$ & & $2.2(1.1)$ & \\
\hline I have not paid rent. ${ }^{\S}$ & & $2.0(1.0)$ & \\
\hline My eating habits have changed. ${ }^{\S}$ & & $2.9(1.3)$ & \\
\hline My household members have changed. ${ }^{\S}$ & & $2.3(1.1)$ & \\
\hline I think I had COVID-19 and was very sick. ${ }^{\S}$ & & $1.7(0.9)$ & \\
\hline $\begin{array}{l}\text { I have family members who have died of } \\
\text { COVID-19. }\end{array}$ & & $2.0(1.2)$ & \\
\hline I have friends who have died of COVID-19.\$ & & $2.6(1.4)$ & \\
\hline $\begin{array}{l}\text { I can no longer get the support of family I once } \\
\text { had. }{ }^{\S}\end{array}$ & & $1.9(1.0)$ & \\
\hline $\begin{array}{l}\text { I can no longer get the support of friends I } \\
\text { once had. }{ }^{\S}\end{array}$ & & $2.1(1.1)$ & \\
\hline
\end{tabular}

Fdifferences in means tested using paired t test, differences in percentages tested using McNemar's test.

$\S$ higher values $=$ stronger agreement (1 to 5$)$.

was kept for our analysis, due to data availability (note the clipping did not affect viewshed). A $1 \mathrm{~m}$ digital elevation model (DEM) was downloaded from USGS, mosaicked, and clipped to the VASS. To account for the influence of building structures on visibility, building footprint data were downloaded from SEMCOG (https://semcog.org/) and checked against project field maps and Google Earth to make sure building footprints were up to date. Building footprints were then rasterized and added to the DEM to create VASS elevation data. To reduce computation load in visibility analysis, we resampled the VASS elevation data to 3-m resolution. The observer locations were generated from the front door of participants' home locations using building footprints. To locate green space in VASS, we used all parks in the metro-Detroit area, and rasterized them to a $1 \mathrm{~m}$-resolution binary raster where a value of 1 indicated parks. Only parks were used due to concerns that vacant lots vs. parks may have different effects on mental health (Nisbet and Zelenski, 2013). Figure 1 illustrates how the viewshed from a participant's home was assessed using these digital data.

Visibility analysis was conducted in ArcGIS Pro 2.6. The observer offset was set to $1.67 \mathrm{~m}$, which is the average height of participants in our study. To quantify the visibility of parks in 


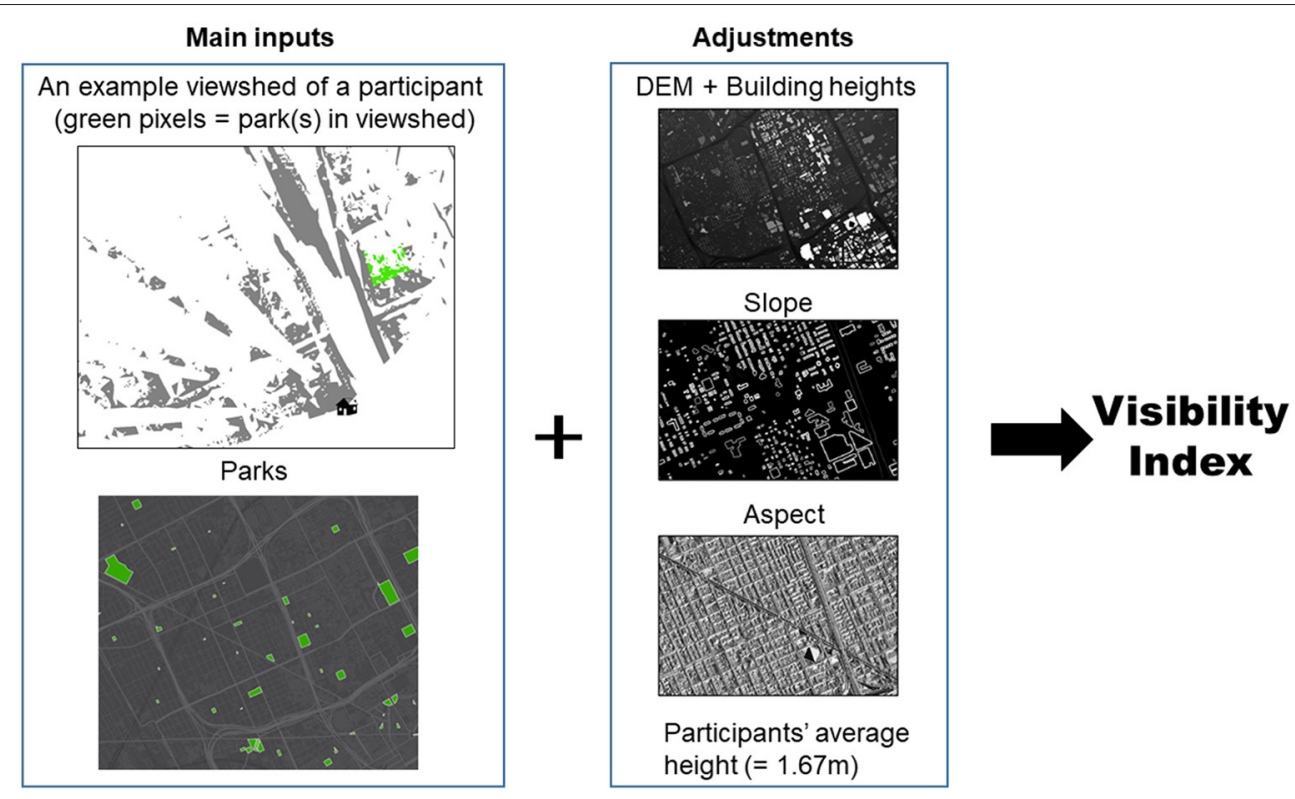

FIGURE 1 | Viewshed analysis process for capturing visibility of greenspace for a participant.

viewsheds from a human perspective (Nutsford et al., 2015), we calculated a Vertical Visibility Index (VVI) from each observer location, whereby we accounted for vertical dimensions of visibility (slope, aspect and elevation). The VVI of parks is calculated as the sum of the weighted pixel values of each visible park cell in the viewshed by adjusting for the vertical degrees of visibility between the eye-level of a human and the top and bottom point of each visible park cell. These values were then grouped into tertiles, to represent each $33 \%$ higher values in visibility of greenspace in our sample $(1=$ none or low visibility; 3 = high visibility).

\section{Statistical Analyses}

To understand our sample, we first conducted descriptive statistics on the demographics, self-reported effects of COVID19 on life conditions, and health status of participants, using data from 2019 and 2020. Only data from participants who participated in both years were included in the analysis $(n=$ 86). To assess potential differences in the full sample from 2019 (including those who did not participate in 2020) and the sample from 2020, we conducted $t$-tests for differences in demographic and health characteristics. We did not detect significant differences in the proportion of females, income, number of children living at home, length of residence, BMI, PSS scores, anxiety or depressive symptoms across the two samples. We did find significantly higher nature-related scores for the full 2019 sample $($ mean $=3.37$ vs. mean $=3.03, p=0.019)$ compared to the 2020 sample.

Next, to explore self-reported use and perceived value of nature changes during, vs. prior to, the pandemic, we tested for significant differences in values over time using a paired $t$-test for continuous data and McNemar's test for paired proportions. We then calculated descriptive statistics on the use and value of nature before (typical month before COVID-19) and during the pandemic (last month) and tested for significant differences using a paired $t$-test.

To explore whether perceptions of access to and use of nature were associated with mental health measures, we first evaluated correlations between our measures and selected only those with $r<0.6$ for model inclusion. Thus, we fitted separate linear regression models for each mental health outcome and included (i) perceived use of neighborhood sidewalks and parks; (ii) perceived accessibility of parks; and (iii) perceived accessibility of sidewalks/shared spaces in the neighborhood. We adjusted for sex, age, married/partner status 2020, stressor score, and the previous year's mental health value (for PSS, anxiety or depression symptoms, respectively).

To explore whether views of greenspace from home were related to mental health outcomes, we first looked descriptively at word clouds of an open response to the survey prompt, "If you have experienced a major stressor in the past 12 months, please let us know what it was," stratified by whether participants had any view of greenspace from home or none. Next, we fitted separate linear regression models for each of the three mental health outcomes and included visibility of greenspace as the independent variable of interest. These models were adjusted for sex, age, married/partner status in 2020, stressor score, and the previous year's mental health value. We selected this small subset of potential confounders because of the small sample size and due to their well-established associations with mental health (Kessler et al., 2007; Scott et al., 2010). All statistical analyses were performed using Stata v16 (Statacorp, College Station, TX, USA).

\section{RESULTS}

The study sample was $83 \%$ African American, 57\% female, and $53 \%$ had an income under $\$ 10,000$ in 2020. From 2019 to 2020, we observed a significant increase in the 
TABLE 2 | Outdoor physical activity and passive enjoyment of nature pre-COVID and during COVID.

\begin{tabular}{|c|c|c|c|c|c|}
\hline & \multicolumn{2}{|c|}{ Pre-COVID } & \multicolumn{2}{|c|}{ Last month } & \multirow[b]{2}{*}{$p$-value ${ }^{\ddagger}$} \\
\hline & Mean & sd & Mean & sd & \\
\hline How often have you engaged in active transportation (commuting by bike or walking) & 3.2 & 1.4 & 2.9 & 1.4 & 0.034 \\
\hline How often have you spent time riding a bicycle for leisure & 2.3 & 1.3 & 2.0 & 1.3 & 0.001 \\
\hline How often have you spent time walking in neighborhood for leisure & 3.1 & 1.1 & 2.9 & 1.3 & 0.003 \\
\hline How often have you spent time walking on trails for leisure & 2.1 & 1.2 & 2.1 & 1.3 & 0.402 \\
\hline How often have you spent time walking in parks for leisure & 2.4 & 1.2 & 2.2 & 1.3 & 0.191 \\
\hline How often have you used trails (>15 min from your house) & 1.9 & 0.9 & 1.8 & 1.0 & 0.754 \\
\hline How often have you used neighborhood resources (sidewalks, parks) & 2.7 & 1.1 & 2.6 & 1.0 & 0.034 \\
\hline How often have you used home-based activity (workouts, housework, yard work, playing outside) & 2.9 & 1.0 & 2.8 & 1.0 & 0.032 \\
\hline How often have you used time outdoors with animals & 2.0 & 1.2 & 1.9 & 1.2 & 0.203 \\
\hline How often have you watched birds through a window & 2.7 & 1.1 & 2.7 & 1.1 & $>0.999$ \\
\hline How often have you listened to birdsong & 2.6 & 1.1 & 2.6 & 1.1 & 0.658 \\
\hline How often have you smelled rain or plants & 2.7 & 1.0 & 2.6 & 1.1 & 0.038 \\
\hline How often have you looked at greenery and plants through a window & 2.9 & 1.0 & 3.0 & 1.1 & $>0.999$ \\
\hline How often have you spent time in your backyard, porch or balcony & 2.9 & 1.1 & 2.9 & 1.1 & 0.698 \\
\hline
\end{tabular}

Higher values = higher frequency over the past month (1 to 5).

$¥$ differences in means tested using paired t test.

Bold font $=$ significant at $p<0.05$ level.

percentage married/partnered (15\% to 33\%), and attitude toward nature (Nature Relatedness 6 (NR-6) scale, 3.0 to 3.3) (Table 1). Unexpectedly, we also observed a significant decrease in perceived stress scores (PSS) (19.8 to 15.8). PSS scores ranging from 14-26 are considered moderate stress. All other demographic and health status measures did not differ significantly over time. In terms of the effects of the pandemic on life conditions, the highest agreement was found for changes in diet, followed by employment stopping and having friends die of COVID-19.

\section{Changes in Self-Reported Use and Value of Nature}

When exploring changes in self-reported outdoor physical activities and passive enjoyment of nature before COVID-19 and during the last month (during COVID-19), we observed significant decreases in active transport, riding a bicycle for leisure, walking in the neighborhood for leisure, use of neighborhood sidewalks and parks, use of home-based activity, and smelling rain or plants (Table 2). We observed an average increase in value of nature (mean $=3.4$, sd $=1.1$, not shown in tabular form) and a significant increase in attitudes toward nature (Table 1).

\section{Perceived Access to Outdoor Spaces as a Buffer Against Poor Mental Health}

When evaluating associations between perceived access to nature and mental health, none of the perceived access measures significantly predicted PSS, anxiety or depressive symptoms (Table 3). Being female, older, and having a higher stressor score were significantly associated with higher depressive symptoms. Similar to Table 4 results, PSS, anxiety and depression scores in 2019 all significantly predicted these same outcomes in 2020. We note however that the association for anxiety and depression (in
Table 3) is somewhat stronger than for PSS, possibly reflecting the more 'trait' like measures of anxiety and depression which tend to remain more stable over time than the more state like measure of PSS which may be more influenced by short-term and recent issues and thus less stable over time.

\section{Nature Views From Home as a Buffer Against Poor Mental Health}

When evaluating associations between visibility of greenspace from home and health outcomes, we found that higher visibility of greenspace was associated with higher perceived stress (Table 4 Model $1, \beta=1.54, p=0.079)$ and anxiety $(\beta$ $=3.97, p=0.025)$. Females also had significantly higher depressive symptoms. Across all three models, the previous year's mental health was a significant predictor of mental health measures in 2020.

Prior to the pandemic, among both those with and without views of greenspace, death and issues with family were common major stressors (Figure 2). After the onset of the pandemic, we can see a clear addition of COVID19 as a major stressor among those with and without views of greenspace. Those without views of greenspace also showed a clear addition of fear as a major stressor. In contrast, those with views of greenspace had more consistent trends in other major stressors including birth, children, and specific family members (especially mother, brother, and sister).

\section{DISCUSSION}

In this predominantly low-income, African American sample, we found that household composition changed during the COVID19 pandemic. Specifically, the proportion of participants who were married or partnered doubled when comparing conditions 
TABLE 3 | Regression modeling results predicting Perceived Stress Scores (PSS), anxiety, and depression symptoms in 2020, inclusion of perceptions of access to nature.

\begin{tabular}{|c|c|c|c|c|c|c|c|c|c|c|c|c|c|c|c|}
\hline \multirow[b]{3}{*}{$\begin{array}{l}\text { Perceived use of neighborhood } \\
\text { sidewalks and parks }\end{array}$} & \multicolumn{5}{|c|}{ Model 1: PSS $\left(R^{2}=0.26\right)$} & \multicolumn{5}{|c|}{ Model 2: Anxiety $\left(R^{2}=0.36\right)$} & \multicolumn{5}{|c|}{ Model 3: Depression symptoms $\left(R^{2}=0.77\right)$} \\
\hline & \multirow{2}{*}{$\begin{array}{c}\boldsymbol{\beta} \\
-0.44\end{array}$} & \multirow{2}{*}{$\begin{array}{c}\text { se } \\
0.69\end{array}$} & \multicolumn{2}{|c|}{$95 \% \mathrm{Cl}$} & \multirow{2}{*}{$\begin{array}{l}\boldsymbol{p} \text {-value } \\
0.531\end{array}$} & \multirow{2}{*}{$\begin{array}{c}\beta \\
0.68\end{array}$} & \multirow{2}{*}{$\begin{array}{c}\text { se } \\
1.32\end{array}$} & \multicolumn{2}{|c|}{$95 \% \mathrm{Cl}$} & \multirow{2}{*}{$\begin{array}{l}\boldsymbol{p} \text {-value } \\
0.611\end{array}$} & \multirow{2}{*}{$\begin{array}{c}\boldsymbol{\beta} \\
0.81\end{array}$} & \multirow{2}{*}{$\begin{array}{c}\text { se } \\
0.80\end{array}$} & \multicolumn{2}{|c|}{$95 \% \mathrm{Cl}$} & \multirow{2}{*}{$\begin{array}{c}\boldsymbol{p} \text {-value } \\
0.319\end{array}$} \\
\hline & & & -1.84 & 0.96 & & & & -1.98 & 3.33 & & & & -0.80 & 2.42 & \\
\hline Perceived accessibility of parks & 0.42 & 0.55 & -0.69 & 1.54 & 0.449 & -0.14 & 0.98 & -2.11 & 1.83 & 0.884 & 0.17 & 0.60 & -1.04 & 1.39 & 0.773 \\
\hline $\begin{array}{l}\text { Perceived accessibility of } \\
\text { sidewalks/shared spaces in } \\
\text { neighborhood }\end{array}$ & -0.82 & 0.58 & -1.99 & 0.35 & 0.164 & 0.11 & 1.04 & -1.97 & 2.20 & 0.913 & -0.16 & 0.62 & -1.40 & 1.08 & 0.801 \\
\hline Female & 1.22 & 1.34 & -1.48 & 3.92 & 0.369 & -1.50 & 2.58 & -6.70 & 3.70 & 0.564 & 3.14 & 1.57 & -0.02 & 6.30 & $0.051^{\star}$ \\
\hline Age & 0.01 & 0.05 & -0.10 & 0.11 & 0.895 & 0.03 & 0.09 & -0.16 & 0.22 & 0.771 & 0.16 & 0.06 & 0.05 & 0.28 & $0.008^{\star \star}$ \\
\hline Married/partnered 2020 & -1.33 & 1.47 & -4.29 & 1.63 & 0.369 & -3.57 & 2.54 & -8.68 & 1.54 & 0.166 & -1.39 & 1.56 & -4.51 & 1.74 & 0.377 \\
\hline Stressor score & 0.03 & 0.53 & -1.04 & 1.09 & 0.960 & -0.06 & 0.99 & -2.05 & 1.93 & 0.952 & 1.05 & 0.57 & -0.08 & 2.19 & $0.069^{\star}$ \\
\hline PSS 2019 & 0.35 & 0.13 & 0.09 & 0.62 & $0.011^{\star \star}$ & & & & & & & & & & \\
\hline Anxiety 2019 & & & & & & 0.56 & 0.12 & 0.31 & 0.80 & $<0.001^{\star \star}$ & & & & & \\
\hline Depression 2019 & & & & & & & & & & & 0.87 & 0.08 & 0.72 & 1.03 & $<0.001^{\star \star}$ \\
\hline
\end{tabular}

${ }^{* *}$ significant at $p<0.05$ level, * significant at $p<0.10$ level.

TABLE 4 | Regression model results, predicting Perceived Stress Scores (PSS), anxiety and depression symptoms in 2020.

\begin{tabular}{|c|c|c|c|c|c|c|c|c|c|c|c|c|c|c|c|}
\hline \multirow[b]{3}{*}{ Visibility of parks from home } & \multicolumn{5}{|c|}{ Model 1: PSS $\left(R^{2}=0.29\right)$} & \multicolumn{5}{|c|}{ Model 2: Anxiety $\left(R^{2}=0.39\right)$} & \multicolumn{5}{|c|}{ Model 3: Depression symptoms $\left(\mathbf{R}^{2}=0.70\right)$} \\
\hline & \multirow{2}{*}{$\begin{array}{c}\boldsymbol{\beta} \\
1.54\end{array}$} & \multirow{2}{*}{$\begin{array}{c}\text { se } \\
0.86\end{array}$} & \multicolumn{2}{|c|}{$95 \% \mathrm{Cl}$} & \multirow{2}{*}{$\begin{array}{l}\boldsymbol{p} \text {-value } \\
0.079^{\star}\end{array}$} & \multirow{2}{*}{$\begin{array}{c}\boldsymbol{\beta} \\
3.97\end{array}$} & \multirow{2}{*}{$\begin{array}{c}\text { se } \\
1.72\end{array}$} & \multicolumn{2}{|c|}{$95 \% \mathrm{Cl}$} & \multirow{2}{*}{$\begin{array}{l}\boldsymbol{p} \text {-value } \\
0.025^{\star \star}\end{array}$} & \multirow{2}{*}{$\begin{array}{c}\boldsymbol{\beta} \\
0.90\end{array}$} & \multirow{2}{*}{$\begin{array}{c}\text { se } \\
1.13\end{array}$} & \multicolumn{2}{|c|}{$95 \% \mathrm{Cl}$} & \multirow{2}{*}{$\begin{array}{c}\boldsymbol{p} \text {-value } \\
0.430\end{array}$} \\
\hline & & & -0.18 & 3.26 & & & & 0.53 & 7.41 & & & & -1.37 & 3.16 & \\
\hline Female & 0.47 & 1.17 & -1.89 & 2.82 & 0.693 & -1.95 & 2.18 & -6.31 & 2.41 & 0.375 & 2.66 & 1.55 & -0.44 & 5.75 & $0.091^{*}$ \\
\hline Age & 0.02 & 0.04 & -0.06 & 0.11 & 0.610 & -0.06 & 0.07 & -0.20 & 0.09 & 0.432 & 0.08 & 0.05 & -0.02 & 0.19 & 0.129 \\
\hline Married/partnered 2020 & -0.82 & 1.29 & -3.42 & 1.77 & 0.525 & -3.20 & 2.28 & -7.75 & 1.36 & 0.166 & -2.47 & 1.65 & -5.77 & 0.84 & 0.140 \\
\hline Stressor score & 0.48 & 0.42 & -0.37 & 1.32 & 0.261 & 0.40 & 0.84 & -1.28 & 2.07 & 0.635 & 0.55 & 0.54 & -0.53 & 1.63 & 0.312 \\
\hline PSS 2019 & 0.41 & 0.12 & 0.17 & 0.64 & $0.001^{\star \star}$ & & & & & & & & & & \\
\hline Anxiety 2019 & & & & & & 0.48 & 0.11 & 0.27 & 0.70 & $<0.001^{\star \star}$ & & & & & \\
\hline Depression 2019 & & & & & & & & & & & 0.80 & 0.07 & 0.65 & 0.94 & $<0.001^{\star \star}$ \\
\hline
\end{tabular}

${ }^{\star *}$ significant at $p<0.05$ level, *significant at $p<0.10$ level.

prior to and during the pandemic. In addition, the number of children living at home decreased somewhat. It is unclear from the current literature how widespread such changes in household composition are. We also observed a significant decrease in perceived stress. In some respects, the decrease in perceived stress might seem surprising, given that a recent study (65\% non-Hispanic whites) showed that depression prevalence during COVID-19 was several-fold higher than prior to the pandemic (Ettman et al., 2020). However, we note first, that perceived stress is not the same as depression symptoms and more reactive to current contexts and situations, and secondly that symptoms of anxiety and depression in a large longitudinal UK cohort also tended to fall over the course of the pandemic as people became more used to the situation (Fancourt et al., 2021). It is therefore possible that the first lockdown (spring 2020) led to some relaxing situations (e.g., less time commuting, ban on evictions and moratorium on water shut-offs) and potentially reduced stress, compared to subsequent waves and on-going pandemic conditions. Other evidence suggests that quality relationships were protective factors for mental health during the pandemic (Pieh et al., 2020). Given the large increase in married/partnered status of our participants, this could contribute to improvements in perceived stress, if such relationships were high quality.

Although participants reported an increase in the value of nature, they also reported decreased contact with nature and/or outdoor physical activity in the form of bicycling or walking in neighborhoods for leisure, active transportation, use of sidewalks and parks, and smelling rain or plants. In contrast to our findings, among a majority white (92\%), high-income sample of residents of Vermont, participation in nature-related physical activity increased for many categories (gardening, hiking, jogging, walking, watching wildlife), and that these changes in activity engagement were associated with demographic characteristics (income, sex, employment) (Morse et al., 2020). Likewise, a survey among educated, older, primarily residents of England (96\%) found that respondents significantly changed their patterns of visiting nature as a 


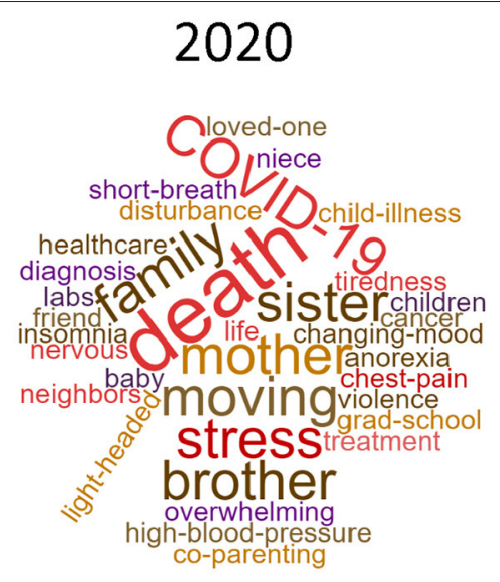

\section{0}

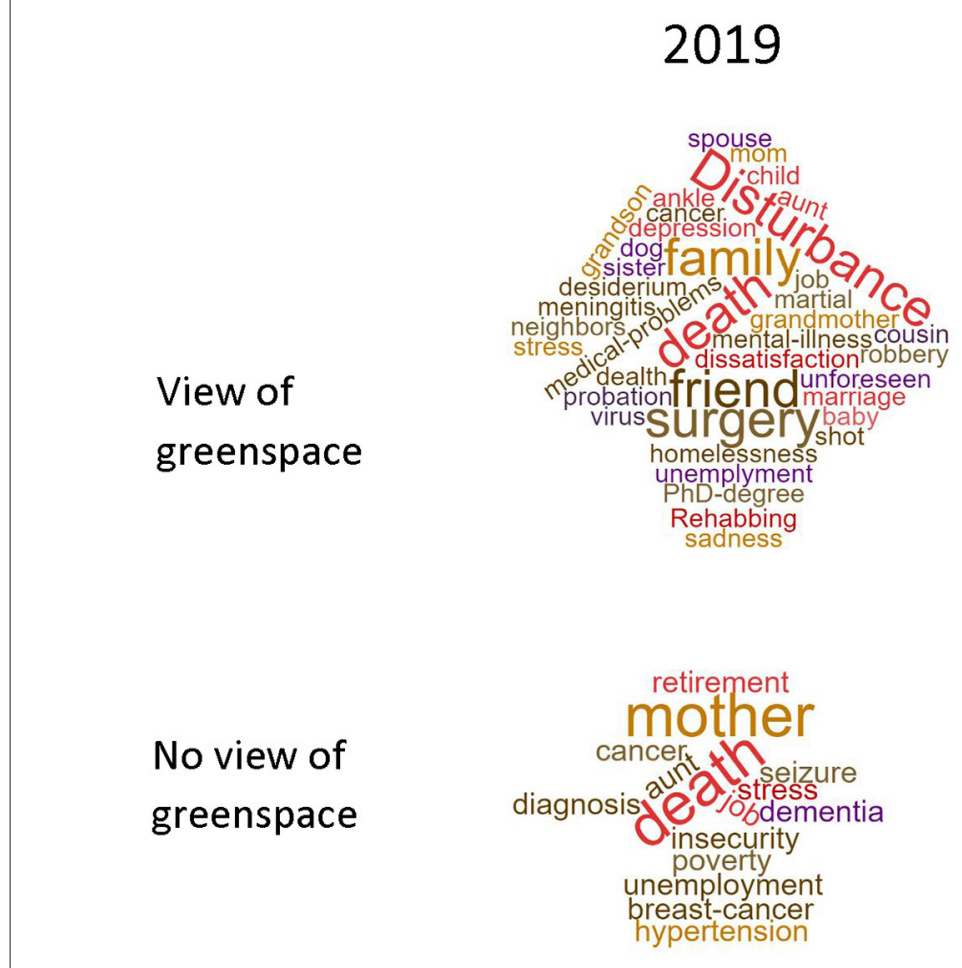

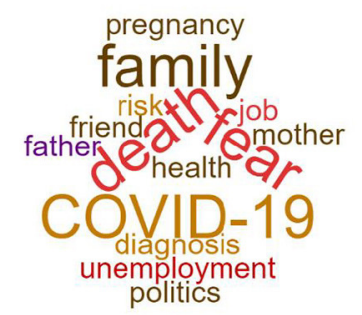

FIGURE 2 | Word clouds for major stressors in 2019 and 2020, stratified by visibility of greenspace from home.

result of the COVID-19 pandemic, whereby people spent more time in nature and visited nature more often during the pandemic (Robinson et al., 2021). Similar to our findings, however, a global study with respondents from 97 countries, restrictions related to COVID-19 found reductions in naturerelated leisure activities (e.g., birding) (Randler et al., 2020). Another study also showed lower levels of time spent outdoors (Cindrich et al., 2021). Similar to our findings, another US-based study has also shown increased value of nature since the start of the pandemic (Morse et al., 2020). It is worth noting that our 2020 sample of participants had significantly lower nature-relatedness scores compared to the full 2019 sample.

When evaluating associations between perceptions of access/use of nature and mental health, none of the perceived access/use variables were associated with stress, anxiety or depressive symptoms. Yet, demographics and COVID-19related stressors were associated with depressive symptoms. We found the most common COVID-19-related stressors were changes in diet, employment stopping, and death of friends from COVID-19. Echoing our findings, a recent study of COVID-19-related stressors and mental health (Ettman et al., 2020) found that exposure to more COVID-related stressors (employment loss, death of a friend or family member, financial problems) was associated with higher risk of depressive symptoms during COVID-19.

When evaluating associations between visibility of nature and mental health, we found significant associations between higher PSS and anxiety and higher visibility of greenspace from home. Compared to the only similar study of its kind to date, Europeans with a self-reported green-blue nature view showed fewer symptoms of depression and anxiety, compared to those with built-up views (Pouso et al., 2020). One of the possible reasons for our finding that higher visibility of greenspaces was associated with poorer mental health is that the quality of the greenspaces within view may be low in these neighborhoods. Specifically, each neighborhood in this study contains an unmaintained park, where the only care is an annual mowing. Therefore, vegetation may be overgrown, usage for conventional purposes may be limited, and these spaces may not promote feelings of relaxation or restoration. Much of the existing research on greenspaces and health during the pandemic involves settings where the quality of parks and their amenities may be much higher. The parent study with which the current analysis is associated will examine the effects of improving park quality on mental health (Pearson et al., 2020).

Other global research noted that nature-based recreation became more directed more toward nearby sites during the pandemic (Randler et al., 2020), and a scoping view recently concluded that the pandemic underscored the importance of accessing green local spaces to engage in physical exercise to improve mental health (Spencer et al., 2020). None of our other measures of access to or use of nature showed significant associations with mental health. Similarly, emerging evidence from older adults in Scotland has also shown that spending 
time in nature (gardening) during the pandemic lockdown, was not associated with changes in health from pre-lockdown levels (Corley et al., 2021).

Taken together, our results indicate that COVID-19 may serve to prolong or exacerbate mental health issues, rather than create them, in this population and that COVID-19-related stressors on life conditions may exacerbate depressive symptoms. Our findings also suggest that views of nature, on their own, may not protect mental health. Future research is needed to understand whether low quality greenspace may limit the ability for nature view to buffer mental health during the pandemic.

\section{Strengths and Limitations}

Strengths of this study include its longitudinal design in lowincome, minority populations and ability to collect high-quality data in a timely manner during the pandemic. We obtained multiple mental health measures and objectively measured views of greenspace, utilizing geospatial techniques. However, several limitations warrant discussion.

First, our small sample size (largely due to pandemic conditions) limits our ability to adjust for multiple potential confounders and to detect significant associations. Also, we did not obtain objective measures of stress (e.g., blood pressure) in 2020, due to restrictions on contact with participants. We also did not collect objective measures of physical activity changes over time (including where activities occurred or how frequently) using accelerometers and GPS devices, due to research restrictions during the pandemic and mobility restrictions placed on residents in efforts to control disease transmission. Our visibility analyses are sensitive to designation of the viewpoint. We used the front door of participants' apartments/houses as the viewpoint. However, even though the analysis involves the 360-degree possible viewshed, when using the front door as the viewpoint, views behind the house may be blocked. In reality, the back of the building could be just within a few steps where a park may be visible. In other words, the visibility analysis calculates the visibility from a single observation point, but in reality, participants' viewing locations can vary (e.g., different sides of their home, facing of windows, etc.). There may be seasonality effects that influence our results in two ways. First, the survey included questions about activities and perceptions during the past month and during a typical month pre-COVID. As such, one may have considered November to be a typical month pre-COVID, while the last month during the survey was May 2020. Environmental conditions, including birdsong, may vary during different months of the year. Second, the 2019 study wave was conducted August-October, while the 2020 study wave was conducted June-July, which may affect responses. Last, we only quantified views of parks, rather than all forms of greenspace, including street trees or vacant lots. We decided not to capture all greenspace using metrics such as NDVI because, in theory, we were concerned that vacant lots vs. parks may have different effects on mental health (Sivak et al., 2021). But, given our findings related to the negative effects of visibility of parks on mental health, future research could specifically examine quality of greenspaces within view.

\section{Policy Implications and Future Research}

Already researchers are grappling with the ways in which COVID-19 might re-shape the ways we use public spaces, city planning and equity into the future (Honey-Roses et al., 2020). Many countries and regions have begun discussions about pedestrian- or bicycle-centered roads, designation of more city greenspaces, or the funding of "green new deals" focused on pandemic economic recovery in areas that could also improve the natural environment and public health. For example, in New Zealand, in May 2020, the government committed to over a billion dollars for "nature jobs," including over 10,000 jobs in environmental work, biodiversity and environmental conservation. In Europe, the Green Deal, aimed at improving the economy in ways that better serve people and bolster resilience, had already been adopted at the time of the pandemic. Its implications go beyond environmental regulation and include social justice and public health issues: "[The deal] aims to protect, conserve and enhance the EU's natural capital, and protect the health and well-being of citizens from environment-related risks and impacts. At the same time, this transition must be just and inclusive" (European Commission, 2019). However, both the EU Green Deal and pandemic economic recovery call for thinking about longer term trends, re-thinking hegemonic sources of funding and investment, and fostering global interdependence and governance. Given the findings of our study, it is important for policy makers to consider heterogeneity in the effects of COVID-19, neighborhood characteristics and cascading life conditions based on sex, ethnicity and income. It is important to remember that poor mental health is not a new issue and that efforts to leverage the pandemic's changes to our everyday lives need to consider core causes of marginalization and income inequality, while advancing efforts to improve environmental conditions and access to high quality greenspace, particularly in racially or ethnically minoritized and lower income neighborhoods.

\section{DATA AVAILABILITY STATEMENT}

The raw data supporting the conclusions of this article will be made available by the authors, without undue reservation.

\section{ETHICS STATEMENT}

The study was approved by the Michigan State University's Institutional Review Board (IRB Approval \#STUDY00000587; date 03/21/2019 and modified for COVID conditions $05 / 26 / 2020$ ). Informed consent was obtained in writing from all participants.

\section{AUTHOR CONTRIBUTIONS}

AP conceived of the study, conducted analyses, with help from JG, and drafted the manuscript. AP, KP, RB, JG, and RH secured funding for this research. WL conducted geospatial analyses, 
under the supervision of AP. All authors edited and approved the manuscript.

\section{FUNDING}

This study was funded by the National Cancer Institute (NCI) of the National Institutes of Health (NIH) 1R01CA239197-01, the Detroit Medical Center, Michigan State University's Clinical Translational Science Initiative, the Vice President for Research

\section{REFERENCES}

Abedi, V., Olulana, O., Avula, V., Chaudhary, D., Khan, A., Shahjouei, S., et al. (2020). Racial, Economic, and Health Inequality and COVID-19 Infection in the United States. Racial Ethn. Health Disparities 8, 732-742. doi: 10.1101/2020.04.26.20079756

Audiometry Questionnaire (AUQ) (2018). 2017-2018 National Heath and Nutrition Examination Survey. Atlanta, GA: Centers for Disease Control and Prevention.

Berman, M. G., Jonides, J., and Kaplan, S. A. (2008). The cognitive benefits of interacting with nature. Psychol. Sci. 19, 1207-1212. doi: $10.1111 / j .1467-9280.2008 .02225 . x$

Cantor, D., Coa, K., Crystal-Mansour, S., Davis, T., Dipko, S., and Sigman, R. (2009). Health Information National Trends Study (HINTS) 2007 Final Report. National Cancer Institute.

Cella, D., Yount, S., Rothrock, N., Gershon, R., Cook, K., Reeve, B., et al. (2007). The Patient-Reported Outcomes Measurement Information System (PROMIS): progress of an NIH roadmap cooperative group during its first two years. Med. Care 45(5 Suppl. 1), S3-S11. doi: $10.1097 / 01 . \mathrm{mlr} .0000258615 .42478 .55$

Cindrich, S. L., Lansing, J. E., Brower, C. S., McDowell, C. P., Herring, M. P., and Meyer, J. D. (2021). Associations between change in outside time pre- and postCOVID-19 public health restrictions and mental health: brief research report. Front. Public Health 9:619129. doi: 10.3389/fpubh.2021.619129

Cohen, S., Kamarck, T., and Mermelstein, R. (1983). A global measure of perceived stress. J. Health Soc. Behav. 24, 385-396. doi: 10.2307/2136404

Corley, J., Okely, J. A., Taylor, A. M., Page, D., Welstead, M., Skarabela, B., et al. (2021). Home garden use during COVID-19: associations with physical and mental wellbeing in older adults. J. Environ. Psychol. 73:101545. doi: 10.1016/j.jenvp.2020.101545

Cox, D. T. C., Shanahan, D. F., Hudson, H. L., Plummer, K. E., Siriwardena, G. M., Fuller, R. A., et al. (2017). Doses of neighborhood nature: the benefits for mental health of living with nature. BioScience 67, 147-155. doi: 10.1093/biosci/biw173

Ettman, C. K., Abdalla, S. M., Cohen, G. H., Sampson, L., Vivier, P. M., and Galea, S. (2020). Prevalence of depression symptoms in US adults before and during the COVID-19 pandemic. JAMA Netw. Open 3:e2019686. doi: 10.1001/jamanetworkopen.2020.19686

European Commission (2019). The European Green Deal Brussels, Belguim: European Commission COM(2019) 640 final. Available online at: https://eurlex.europa.eu/legal-content/EN/TXT/HTML/?uri=CELEX:52019DC0640\& from=ET (accessed December 11, 2019)

Fancourt, D., Steptoe, A., and Bu, F. (2021). Trajectories of anxiety and depressive symptoms during enforced isolation due to COVID-19 in England: a longitudinal observational study. Lancet Psychiatry 8, 141-149. doi: 10.1016/S2215-0366(20)30482-X

Forsyth, A., Oakes, J. M., and Schmitz, K. H. (2009). Test-retest reliability of the twin cities walking survey. J. Phys. Act. Health 6, 119-131. doi: 10.1123/jpah.6.1.119

Frumkin, H., Bratman, G. N., Breslow, S. J., Cochran, B., Kahn, P. H. Jr., Lawler, J. J., et al. (2017). Nature contact and human health: a research agenda. Environ. Health Perspect. 125:075001. doi: 10.1289/EHP1663

Hays, R. D., Bjorner, J. B., Revicki, D. A., Spritzer, K. L., and Cella, D. (2009). Development of physical and mental health summary scores from the Patient-Reported Outcomes Measurement Information System (PROMIS) and Graduate Studies, and the Provost Undergraduate Research Initiative. Salary for $\mathrm{TH}$ is provided by the Negaunee Foundation.

\section{ACKNOWLEDGMENTS}

The authors wish to acknowledge Ventra Asana for her leadership of the Detroit field team. We also wish to thank the study participants, without whom this project would not be possible. global items. Qual. Life Res. 18, 873-880. doi: 10.1007/s11136-0099496-9

Honey-Roses, J., Anguelovski, I., Bohigas, J., Chireh, V., Daher, C., Konijnendijk, C., et al. (2020). The Impact of COVID-19 on Public Space: A Review of the Emerging Questions. Cities and Health. doi: 10.31219/osf.io/rf7xa

Kessler, R. C., Angermeyer, M., Anthony, J. C., De Graaf, R., Demyttenaere, K., Gasquet, I., et al. (2007). Lifetime prevalence and age-of-onset distributions of mental disorders in the World Health Organization's World Mental Health Survey Initiative. World Psychiatry 6, 168-176.

Kuo, M. (2015). How might contact with nature promote human health? Promising mechanisms and a possible central pathway. Front. Psychol. 6:1093. doi: $10.3389 /$ fpsyg. 2015.01093

Mackey, K., Ayers, C. K., Kondo, K. K., Saha, S., Advani, S. M., Young, S., et al. (2020). Racial and ethnic disparities in covid-19-related infections, hospitalizations, and deaths: a systematic review. Ann. Intern. Med. J. 174, 362-373 doi: 10.7326/M20-6306

Morse, J. W., Gladkikh, T. M., Hackenburg, D. M., and Gould, R. K. (2020). COVID-19 and human-nature relationships: vermonters' activities in nature and associated nonmaterial values during the pandemic. PLOS ONE 15:e0243697. doi: 10.1371/journal.pone.0243697

National Eye Institute (2000). Vision Function Questionnaire 25, Self-Administered Format. Methesda, MD: NEI.

Nebeling, L. C., Hennessy, E., Oh, A. Y., Dwyer, L. A., Patrick, H., Blanck, H. M., et al. (2017). The FLASHE study: survey development, dyadic perspectives, and participant characteristics. Am. J. Prev. Med. 52, 839-848. doi: 10.1016/j.amepre.2017.01.028

NHANES (2010). Dietary Screener Questionnaires (DSQ) in the NHANES 200910: DSQ. Bethesda, MD: NIH.

NHANES (2018). NHANES 2017-2018 Questionnaire Instruments CDC/National Center for Health Statistics. Bethesda, MD: NIH.

Nisbet, E., and Zelenski, J. (2013). The NR-6: a new brief measure of nature relatedness. Front. Psychol. 4:813. doi: 10.3389/fpsyg.2013.00813

Nutsford, D., Reitsma, F., Pearson, A. L., and Kingham, S. (2015). Personalising the viewshed: visibility analysis from the human perspective. Appl. Geogr. 62, 1-7. doi: 10.1016/j.apgeog.2015.04.004

Pearson, A. L., Pfeiffer, K. A., Gardiner, J., Horton, T., Buxton, R. T., Hunter, R. F., et al. (2020). Study of active neighborhoods in Detroit (StAND): study protocol for a natural experiment evaluating the health benefits of ecological restoration of parks. BMC Public Health 20:683. doi: 10.1186/s12889-020-08716-3

Pieh, C., O'Rourke, T., Budimir, S., and Probst, T. (2020). Relationship quality and mental health during COVID-19 lockdown. PLoS ONE 15:e0238906. doi: 10.1371/journal.pone.0238906

Portegijs, E., Keskinen, K. E., Tuomola, E.-M., Hinrichs, T., Saajanaho, M., and Rantanen, T. (2021). Older adults' activity destinations before and during COVID-19 restrictions: from a variety of activities to mostly physical exercise close to home. Health Place 68:102533. doi: 10.1016/j.healthplace.2021.1 02533

Pouso, S., Borja, A., Fleming, L. E., Gómez-Baggethun, E., White, M., and Uyarra, M. C. (2020). Maintaining Contact With Blue-Green Spaces During the COVID19 Pandemic Associated With Positive Mental Health. Sci. Total Environ. 756: 143984. doi: 10.31235/osf.io/gpt3r

Prouse, V., Grant, J., Ramos, H., and Radice, M. (2015). Assessing Neighbourhood Change: Gentrification and Suburban Decline in a Mid-Sized City. Halifax: School of Planning, Dalhousie University. 
Ramos, H., Gosse, M., Pritchard, P., Radice, M., Grant, J., Shakotko, P., et al. (2016). "How Haligonians perceive neighborhood change," in May 2016 NCRP Research Symposium Presentation (Toronto).

Randler, C., Tryjanowski, P., Jokimaki, J., Kaisanlahti-Jokimaki, M. L., and Staller, N. (2020). SARS-CoV2 (COVID-19) pandemic lockdown influences naturebased recreational activity: the case of birders. Int. J. Environ. Res. Public Health 17:7310. doi: 10.3390/ijerph17197310

Robinson, J. M., Brindley, P., Cameron, R., MacCarthy, D., and Jorgensen, A. (2021). Nature's Role in Supporting Health During The COVID-19 Pandemic: A Geospatial and Socioecological Study. Environ. Res. Public Health 18:2227. doi: 10.20944/preprints202101. 0125.v1

Saelens, B. E., Sallis, J. F., Black, J. B., and Chen, D. (2003). Neighborhood-based differences in physical activity: an environment scale evaluation. Am. J. Public Health 93:1552-1558. doi: 10.2105/AJPH.93.9.1552

Schroeder, P., and Wilbur, M. (2013). 2012 National Survey of Bicyclist and Pedestrian Attitudes and Behavior: Findings Report. Washington, DC: National Highway Traffic Safety Administration. Contract No.: DOT HS $811841 \mathrm{~B}$.

Scott, K. M., Wells, J. E., Angermeyer, M., Brugha, T. S., Bromet, E., Demyttenaere, K., et al. (2010). Gender and the relationship between marital status and first onset of mood, anxiety and substance use disorders. Psychol. Med. 40, 1495-1505. doi: 10.1017/S0033291709991942

Shanahan, D. F., Bush, R., Gaston, K. J., Lin, B. B., Dean, J., Barber, E., et al. (2016). Health benefits from nature experiences depend on dose. Sci Rep. 6:28551. doi: $10.1038 /$ srep28551

Sivak, C. J., Pearson, A. L., and Hurlburt, P. (2021). Effects of vacant lots on human health: a systematic review of the evidence. Landsc. Urban Plan. 208:104020. doi: 10.1016/j.landurbplan.2020.104020

Spencer, L. H., Lynch, M., Lawrence, C. L., and Edwards, R. T. (2020). A scoping review of how income affects accessing local green space to engage in outdoor physical activity to improve well-being: implications for post-COVID-19. Int. J. Environ. Res. Public Health 17:9313. doi: 10.3390/ijerph17249313

Taylor, L., Hahs, A. K., and Hochuli, D. F. (2017). Wellbeing and urban living: nurtured by nature. Urban Ecosystems 21, 197-208. doi: $10.1007 /$ s11252-017-0702-1
Tirupathi, R., Muradova, V., Shekhar, R., Salim, S. A., Al-Tawfiq, J. A., and Palabindala, V. (2020). COVID-19 disparity among racial and ethnic minorities in the US: a cross sectional analysis. Travel Med. Infect. Dis. 38:101904. doi: 10.1016/j.tmaid.2020.101904

van Houwelingen-Snippe, J., van Rompay, T. J. L., and Ben Allouch, S. (2020). Feeling connected after experiencing digital nature: a survey study. Int. J. Environ. Res. Public Health 17:6879. doi: 10.3390/ijerph17186879

Volenec, Z. M., Abraham, J. O., Becker, A. D., and Dobson, A. P. (2021). Public parks and the pandemic: how park usage has been affected by COVID-19 policies. PLoS ONE 16:e0251799. doi: 10.1371/journal.pone.0251799

Xiao, X., Perry, E., Manning, R., Krymkowski, D., Valliere, W., and Reigner, N. (2017). Effects of transportation on racial/ethnic diversity of national park visitors. Leis. Sci. 39, 126-143. doi: 10.1080/01490400.2016.1151846

Yang, Y., and Xiang, X. (2021). Examine the associations between perceived neighborhood conditions, physical activity and mental health during the COVID-10 pandemic. Health Place 67:102505. doi: $10.1016 /$ j.healthplace.2021.102505

Conflict of Interest: The authors declare that the research was conducted in the absence of any commercial or financial relationships that could be construed as a potential conflict of interest.

Publisher's Note: All claims expressed in this article are solely those of the authors and do not necessarily represent those of their affiliated organizations, or those of the publisher, the editors and the reviewers. Any product that may be evaluated in this article, or claim that may be made by its manufacturer, is not guaranteed or endorsed by the publisher.

Copyright (C) 2021 Pearson, Horton, Pfeiffer, Buxton, Gardiner, Liu, Hunter and White. This is an open-access article distributed under the terms of the Creative Commons Attribution License (CC BY). The use, distribution or reproduction in other forums is permitted, provided the original author(s) and the copyright owner(s) are credited and that the original publication in this journal is cited, in accordance with accepted academic practice. No use, distribution or reproduction is permitted which does not comply with these terms. 